\title{
BARREIRAS A LIVRE ACESSIBILIDADE NA UNIVERSIDADE ESTADUAL DE MARINGÁ- PR
}

\author{
Silvana De Jesus Galdino ${ }^{1}$
}

\author{
Camila Lima Chechin Camacho Arrebola ${ }^{2}$
}

\author{
Ana Carla Fernandes Gasques ${ }^{3}$
}

\begin{abstract}
RESUMO
O objetivo desta pesquisa é identificar e avaliar os principais pontos críticos de acessibilidade dentro da Universidade Estadual de Maringá e avaliar o enquadramento dos mesmos quanto às normas, de modo a fornecer subsídios para futuros trabalhos que contribuam para melhor planejamento de espaços públicos. O termo acessibilidade pode ser entendido como a possibilidade que um indivíduo tem de compreender e interagir com o espaço urbano, bem como de comunicar-se com outros cidadãos, tendo ou não limitações de mobilidade ou de percepção sensorial. Promover acessibilidade representa uma das condições essenciais para assegurar a qualquer cidadão brasileiro o direito constitucional de ir e vir. A pesquisa foi dividida em duas etapas: analítica teórica caracterizada pelo levantamento bibliográfico, referencial teórico e vistoria in loco para identificar e avaliar os pontos críticos de acessibilidade na Universidade Estadual de Maringá. Além de calçadas irregulares, que podem contribuir para a queda ou impossibilidade de locomoção do deficiente, foram encontradas também rampas fora dos padrões estabelecidos, além de não contar com guia tátil ou corrimão em ambas as extremidades.
\end{abstract}

Palavras-chave: Acessibilidade; Mobilidade; UEM.

\section{BARRIERS TO ACCESSIBILITY IN UNIVERSITY FREE STATE}

\section{MARINGA- PR}

\begin{abstract}
The objective of this research is to identify and assess the main critical points of accessibility within the State University of Maringa and evaluate the framework of the same as the rules in order to provide insights for future activities to bring about better planning of public spaces. The term accessibility can be understood as the possibility that an individual has to understand and

\footnotetext{
${ }^{1}$ Bacharel em Geografia, Mestre em Engenharia Urbana/Universidade Estadual de MaringáUEM, PR. E-mail.silgaldino@outlook.com

${ }^{2}$ Arquiteta e Urbanista, Mestre em Engenharia Urbana/Universidade Estadual de Maringá-UEM, PR. E-mail.carrebola33@hotmail.com

${ }^{3}$ Bacharel em Engenharia Ambiental, Mestre em Engenharia Urbana/Universidade Estadual de Maringá-UEM, PR. E-mail. Anacarlafgasques@hotmail.com
} 


\section{Periódica Eletrônica

interact with the urban space as well as to communicate with other citizens, whether or not limited mobility or sensory perception. Promoting accessibility is an essential condition to ensure any Brazilian citizen the constitutional right to come and go. The research was divided into two stages: theoretical analytical characterized by literature, theoretical and survey in place to identify and assess critical issues of accessibility at the State University of Maringa. In addition to uneven sidewalks, which can contribute to the fall or poor motor restlessness, they were also found ramps outside the established standards, and not rely on tactile guide or handrails on both ends.

Key words: accessibility; mobility; UEM

\section{BARRERAS A LA ACCESIBILIDAD EN LA UNIVERSIDAD LIBRE DEL ESTADO MARINGA- PR}

\section{RESUMEN}

El objetivo de esta investigación es identificar y evaluar los principales puntos críticos de accesibilidad dentro de la Universidad Estadual de Maringá y evaluar el marco de las mismas que las reglas con el fin de proporcionar información para futuras actividades para lograr una mejor planificación de los espacios públicos. El término accesibilidad puede ser entendida como la posibilidad de que un individuo tiene de entender e interactuar con el espacio urbano, así como de comunicarse con los demás ciudadanos, sean o no limita la movilidad o la percepción sensorial. La promoción de la accesibilidad es una condición esencial para asegurar que cualquier ciudadano brasileño el derecho constitucional de ir y venir. La investigación se dividió en dos fases: teórica analítica que se caracteriza por la literatura, la teórica y la encuesta en el lugar para identificar y evaluar los temas críticos de la accesibilidad en la Universidad Estatal de Maringá. Además de las aceras irregulares, que pueden contribuir a la caída o pobre inquietud motora, también se encontraron rampas fuera de las normas establecidas, y no dependen de guía táctil o pasamanos en ambos extremos.

Palabras clave: Accesibilidad; Movilidad; UEM

\section{INTRODUÇÃO}

Embora o termo acessibilidade seja amplamente discutido em termos de planejamento, a maioria das cidades brasileiras ainda não consegue garantir infraestrutura adequada aos seus usuários (AGUIAR, 2010). Em todo o mundo, a persistência de barreiras no processo de busca e utilização dos serviços gera oportunidades diferenciadas entre os grupos sociais na obtenção do cuidado em saúde, que muitas vezes caracterizam situações de injustiça social (TRAVASSOS; CASTRO, 2008).

A principal dificuldade está em garantir acessibilidade em espaços de uso comum dos cidadãos, dentre estes se incluem as universidades, as quais 


\section{Periódica Eletrânica \\ Fórum Ambiental}

da Alta Paulista
Volume 11, Número 09, 2015

Produção e as

Tecnologias Sustentáveis

deveriam ser sinônimas de mobilidade e acessibilidade. As universidades são mundialmente reconhecidas como paradigma da democracia, em função disso, seu planejamento espacial deveria promover acessibilidade a todos, compreendendo a eliminação de barreiras arquitetônicas e sociais para pessoas com deficiência física ou mobilidade reduzida (SOARES et al, 2007).

De acordo com a Norma NBR 9.050 (ABNT, 2004), acessibilidade é definida como possibilidade e condição de alcance, percepção e entendimento para a utilização com segurança e autonomia de edificações, espaços, mobiliário, equipamento urbano e elementos. todos os espaços de uso comum que venham a ser projetados, construídos, reformados, ampliados, bem como, equipamentos devem atender as normas para ser considerados acessíveis (ABNT NBR 9.050/2004).

Transpor barreiras e se sentir capaz, é um direito de todos os cidadãos. Atender as necessidades de estudo, trabalho e lazer significa garantir condições necessárias ao acesso a todos os locais, contribuindo de forma ativa no desenvolvimento da sociedade e derrubando discriminações existentes (NUNES et al, 2007).

O desenho do espaço e as características físicas influenciam de maneira direta e indiretamente na mobilidade e acessibilidade das pessoas, como por exemplo: a largura, inclinação longitudinal e transversal de rampas; estado de conservação do piso de acesso entre ambientes internos e externos, bem como a inexistência de sinalização adequada (AGUIAR 2010).

Outros fatores também podem comprometer a mobilidade a ambientes desejáveis, tais como: a forma de uso e ocupação do solo adjacente as calçadas, rampas fora das normas estabelecidas por lei, equipamentos localizados em locais inadequados, degraus e passeios degradados, dificultando a acessibilidade de cadeirantes, usuário de muletas, deficientes visuais, dentre outros (MARTINS; AUGUSTO, 2012).

Para Martins e Augusto (2012), a maior limitação das pessoas não está em sua deficiência física ou motora e sim na inadequação do espaço construído de acordo com as normas vigentes. Desta forma, os indivíduos com mobilidade reduzida não conseguem ter acesso aos espaços como um direito 
universal. Sendo assim, a acessibilidade é também uma questão de qualidade de vida e está relacionada a fatores como o conforto e a segurança.

As universidades são mundialmente reconhecidas como paradigma da democracia, em função disso, seu planejamento espacial deveria promover acessibilidade a todos, compreendendo a eliminação de barreiras arquitetônicas e sociais para pessoas com deficiência física ou mobilidade reduzida (NUNES et al, 2007).

De acordo com Costa e Meira (2008), o espaço construído exerce um papel fundamental na superação das desigualdades físicas e sociais; e dentre eles, os espaços de ensino são particularmente importantes, em especial o espaço das instituições públicas de ensino superior, reconhecidas como paradigma da democracia.

Para Duarte e Cohen (2004), "o espaço universitário" é reconhecido como um paradigma da democracia, portanto o acesso não deveria significar apenas a possibilidade das camadas mais pobres da sociedade chegarem a universidade, mas, também, a eliminação de quaisquer barreiras físicas e sociais as pessoas com deficiência sensorial, física e metal, temporária ou permanente.

Edificações públicas ou privadas de uso comum, tais como, escolas, universidades, bibliotecas, postos de saúde, bares, restaurantes, agências bancárias, clubes, devem oferecer garantia de acessibilidade a todos os usuários (CPA, 2005).

Diante do exposto, esta pesquisa teve por objetivo identificar e avaliar alguns pontos críticos de acessibilidade dentro da Universidade Estadual de Maringá e o enquadramento quanto às normas de acessibilidade, de modo a fornecer subsídios para futuros trabalhos que contribuam para melhor planejamento de espaços públicos.

Esta pesquisa se fundamentou na atual legislação ABNT, NBR9050/2004 que trata da prioridade de atendimento de pessoas com deficiência e estabelece normas gerais e critérios básicos para a promoção da acessibilidade em espaços, imobiliários, edificações e espaços urbanos. 


\section{MATERIAL E MÉTODOS}

A área urbana de Maringá está situada ao norte do estado do Paraná, com centro nas coordenadas $27^{\circ} 27^{\prime}$ de Latitude Sul e 51057' de Longitude Oeste cortada pelo trópico de Capricórnio. Apresenta uma variação altimétrica de 450 a 600 m em relação ao nível do mar e uma área de 487 Km² (IBGE, 2013).

O Campus sede, localizado na Avenida Colombo № 5.790 (Figura 1), com mais de 1 milhão de $\mathrm{m}^{2}$ (Figura 1), está localizado em Maringá, no noroeste do Paraná, município com cerca de 300 mil habitantes, com economia baseada na agroindústria e na prestação de serviços (IBGE,2013).

Figura 1: Localização da Universidade Estadual de Maringá-UEM

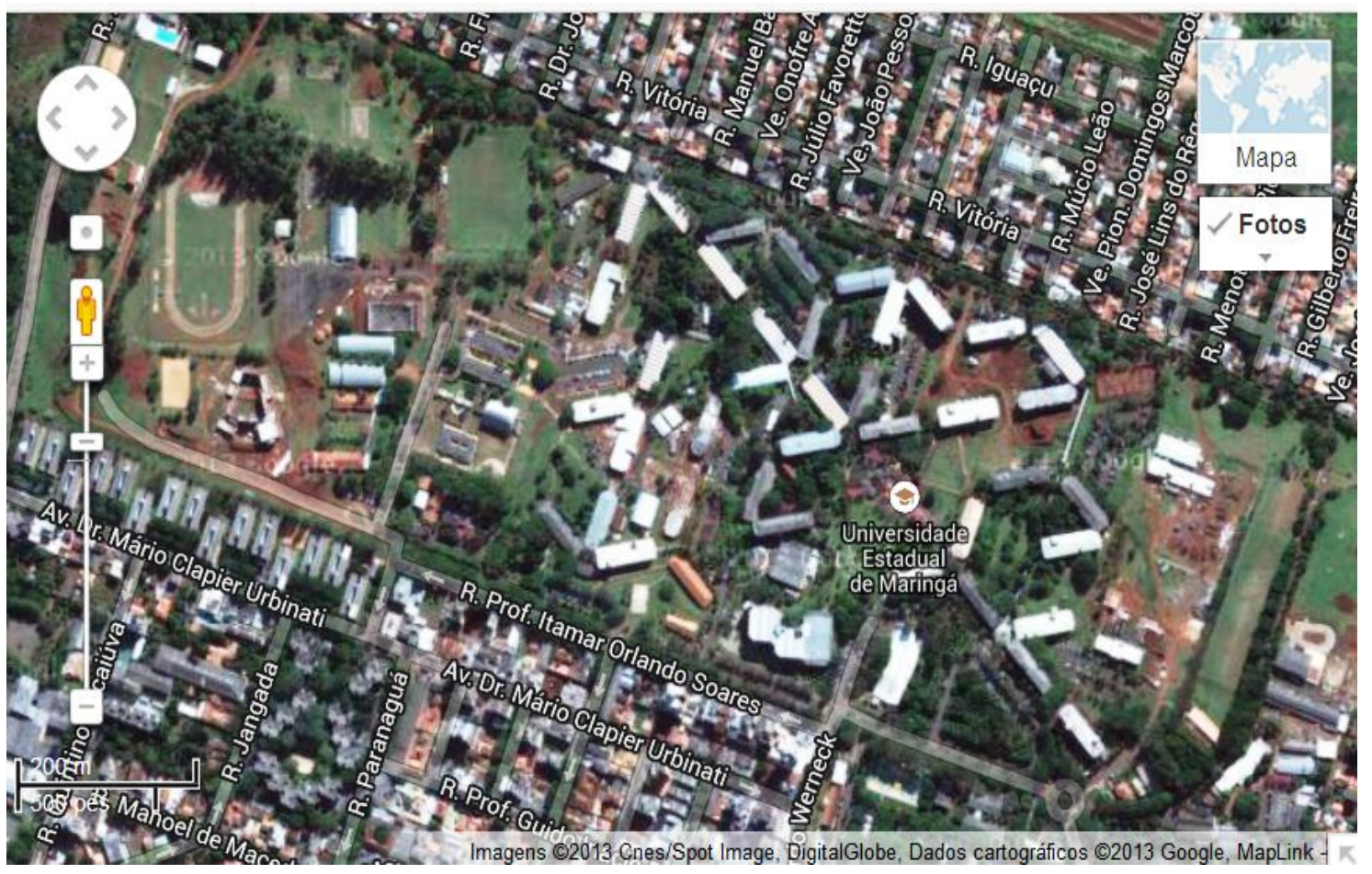

Fonte: Google Maps, 2014

De acordo com a Comissão Própria de Avaliação, Portaria №. 1.193/2005-GRE (2005), a Universidade Estadual de Maringá surgiu em 1969, sendo reconhecida em 11/05/1976. Atualmente a instituição possui uma comunidade universitária formada por mais de 20 mil pessoas, entre alunos, 


\section{Periádica Eletrânica

professores e funcionários. Oferece 52 cursos de graduação, 93 de especialização, 28 de mestrado e 12 de doutorado.

Considerada uma das melhores universidades do Brasil, sendo vista como a melhor do estado do Paraná, com cursos de destaque em âmbito nacional, atraindo estudantes de todo o país. Fator que justifica a existência de grande diversidade de pessoas atendidas e a necessidade de adequar a velha infraestrutura às normas de acessibilidade e mobilidade.

A pesquisa foi dividida em duas etapas: analítica teórica caracterizada pelo levantamento bibliográfico, referencial teórico e vistoria in loco para identificar e avaliar os pontos críticos de acessibilidade na Universidade Estadual de Maringá.

\section{RESULTADOS E DISCUSSÃO}

Ao abordar questões pertinentes a inclusão e acessibilidade de pessoas com algum grau de deficiência definitiva ou temporária, é comum a referencia imediata aos aspectos relativos as barreiras arquitetônicas por serem bastante visíveis. A acessibilidade física é uma necessidade básica para que todas as pessoas possam desenvolver suas atividades cotidianas com segurança e comodidade.

Leis federais, estaduais e municipais, bem como decretos e estatutos abordam a temática acessibilidade como um direito de todos e de qualquer pessoa. No entanto, o que se observou na prática na Universidade Estadual de Maringá - UEM é uma realidade bem diferente, ou seja, condições que atendem ao disposto nas normas.

Atualmente a Universidade Estadual de Maringá-UEM, apresenta algumas falhas quanto a acessibilidade de pessoas com mobilidade reduzida. Enfrenta um grande desafio quanto a universalização da acessibilidade, adequação das edificações de acordo com o conceito de Desenho Universal e a legislação vigente. Portanto, faz-se necessário adequar a infraestrutura existente de forma a eliminar as barreiras arquitetônicas, proporcionando a toda a clientela atendida, acesso e livre circulação. 
O primeiro aspecto encontrado, refere-se a pavimentação (Figura $2 \mathrm{~A}$ ), que, além da presença de folhas em excesso, também encontra-se degradada, seja por falta de manutenção ou pelo fato de árvores, postes ou caixas de inspeção estarem obstruindo a passagem e dificultando o acesso de pessoas cadeirantes ou carrinhos de bebê ou outras pessoas com limitações (Figura 2B).

Figura 02: Pavimentação degradada com presença de vegetação arbórea no calçamento.
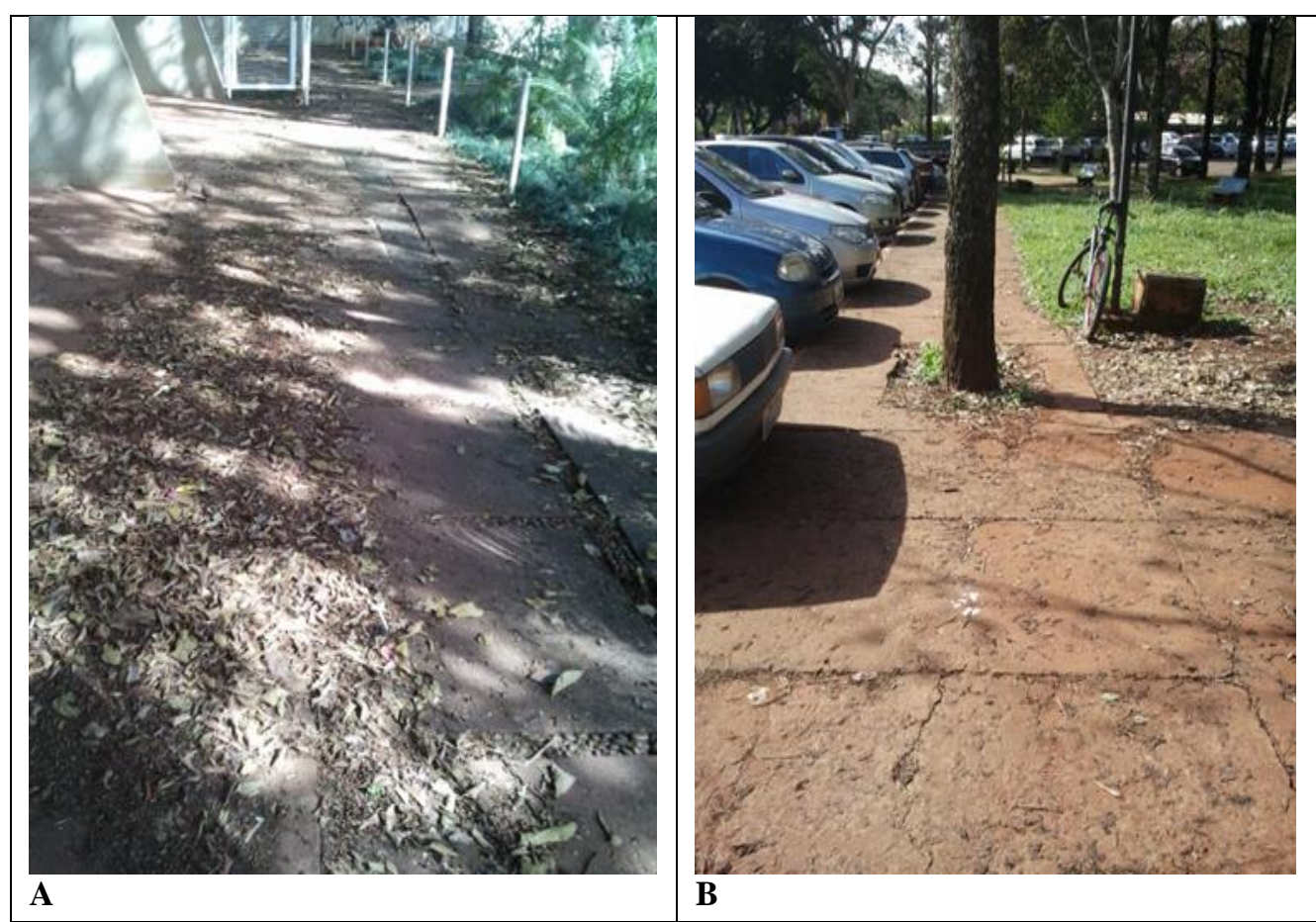

Fonte: Acervo pessoal, 2014

Também podemos destacar a existência de uma arborização antiga nas imediações de acesso aos blocos e ao entorno dos limites da faculdade, acarretando em excesso de folhas e galhos na pavimentação, dificultando o deslocamento das pessoas e obstruindo calçadas e equipamentos instalados nas imediações. De acordo com as normas ABNT, NBR 9050/2004, os espaços das calçadas destinadas a circulação de pessoas deve ser livre de obstáculos, seja eles temporários ou permanentes.

$O$ próximo aspecto observado refere-se às dificuldades de acessibilidade em função de barreiras arquitetônicas (Figuras 3A, 3B), pois em vários locais de acesso a instituição há barras de ferro para evitar acesso de 
motos e bicicletas, porém, estas prejudicam também o acesso de pessoas com algum tipo de limitação.

Figura 3: Barreiras dificultando o livre acesso de pessoas com limitação de locomoção

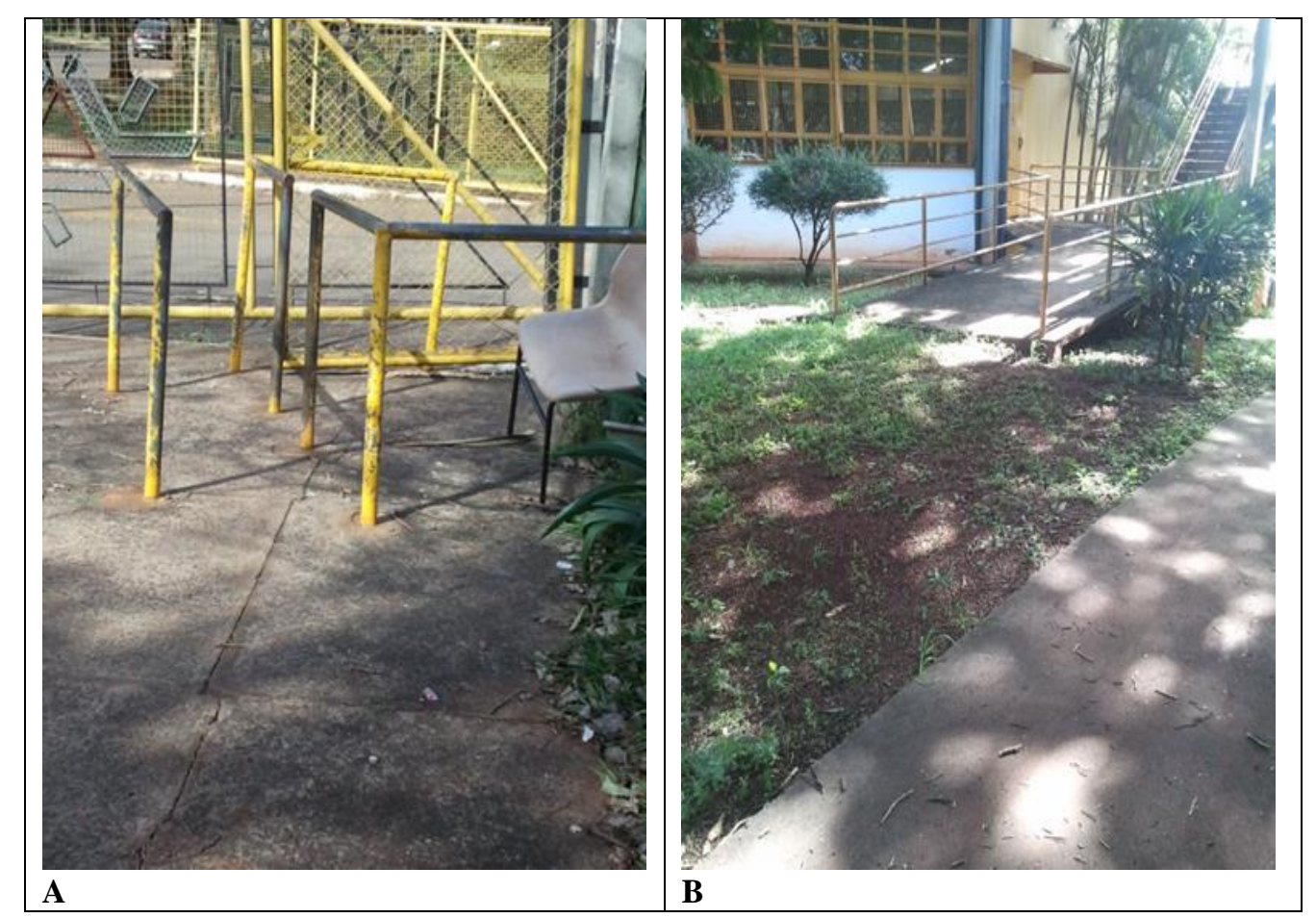

Fonte: Acervo pessoal, 2014

De acordo com a ABNT NBR 9.050 (ABNT, 2004), rampas devem ter características específicas: inclinação transversal não pode exceder $2 \% \mathrm{em}$ rampas internas e 3\% em rampas externas; projeção de corrimão de $10 \mathrm{~cm}$ para cada lado, sendo a largura da mesma, de acordo com o fluxo de pessoas. Desníveis em rotas acessíveis com até $5 \mathrm{~mm}$ não necessitam de tratamento especial, no entanto, desníveis entre $5 \mathrm{~mm}$ a $15 \mathrm{~mm}$ devem ser tratados como rampas, acima de $15 \mathrm{~mm}$, atender aos quesitos de rampas e degraus com devida sinalização (ABNT NBR 9.050, 2004).

Nas Figuras 4A e 4B observa-se as deficiências em infraestrutura adequada no que se referem às rampas. Segundo a Lei ABNT NBR 9.050, para os espaços se tornarem acessíveis, faz-se necessário rever desenho arquitetônico, infraestrutura implantada de acesso entre ambientes internos e externos, de maneira a facilitar a acessibilidade de pessoas que apresentam dificuldades de locomoção. 
Figura 4: Rampas com inclinação a cima do permitido e sem sinalização adequada

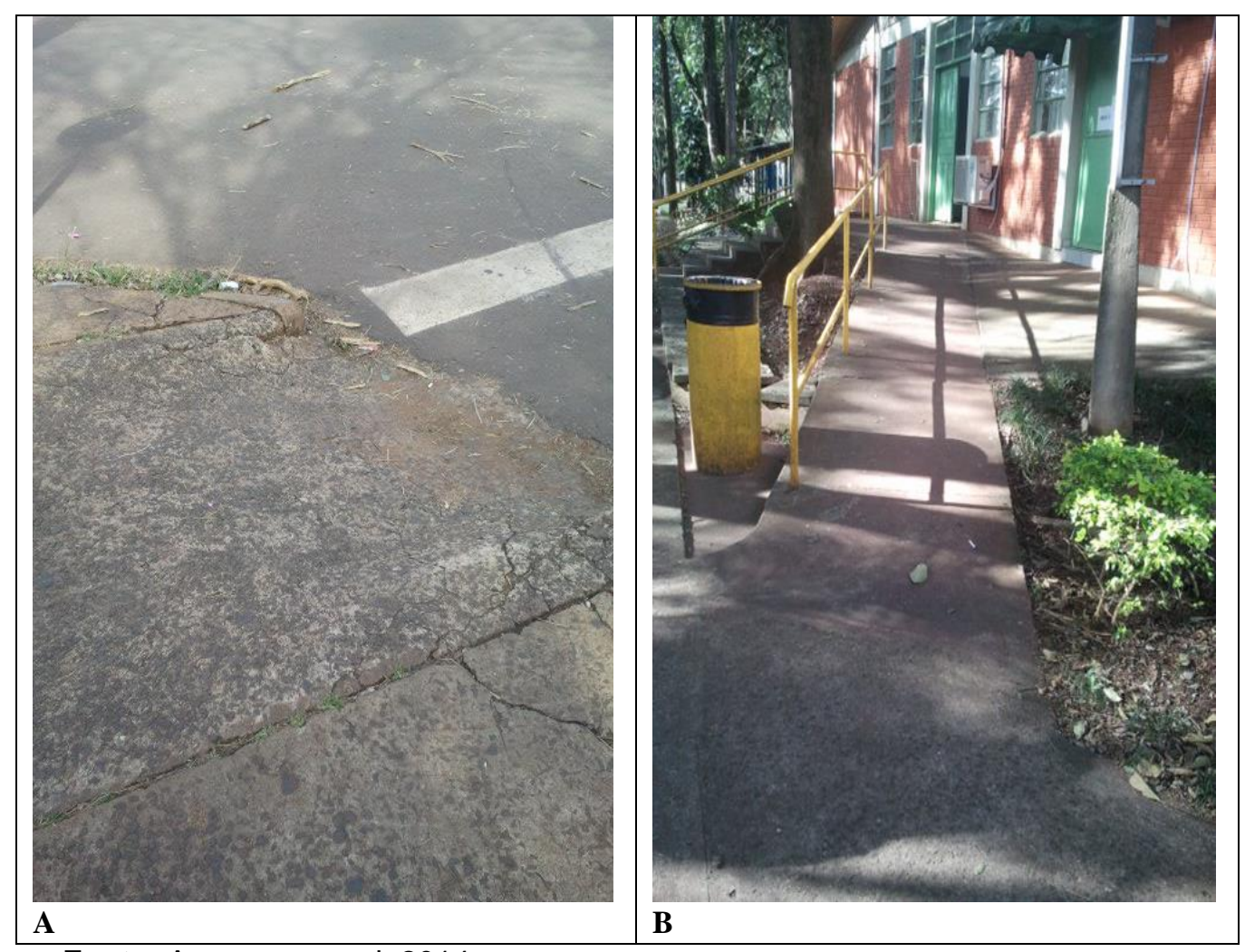

Fonte: Acervo pessoal, 2014

Em vários pontos analisados, é possível perceber a descontinuidade de rampas, desníveis fora do padrão, acima do permitido nas normas $A B N T$, NBR9050/2004 e a ausência de acessos (Figura 5 A). A ausência de sinalização com piso tátil direcional e de alerta também se caracteriza como obstáculos para pessoas com mobilidade reduzida, podendo gerar transtornos e riscos de acidentes (Figura $5 \mathrm{~B}$ ). A instalação de piso tátil direcional, de alerta e rampas com livre acesso faz-se necessário para o deslocamento seguro e acessível aos ambientes.

Figura 5: Rampa com desnível inadequado e descontinuidade de piso tátil 


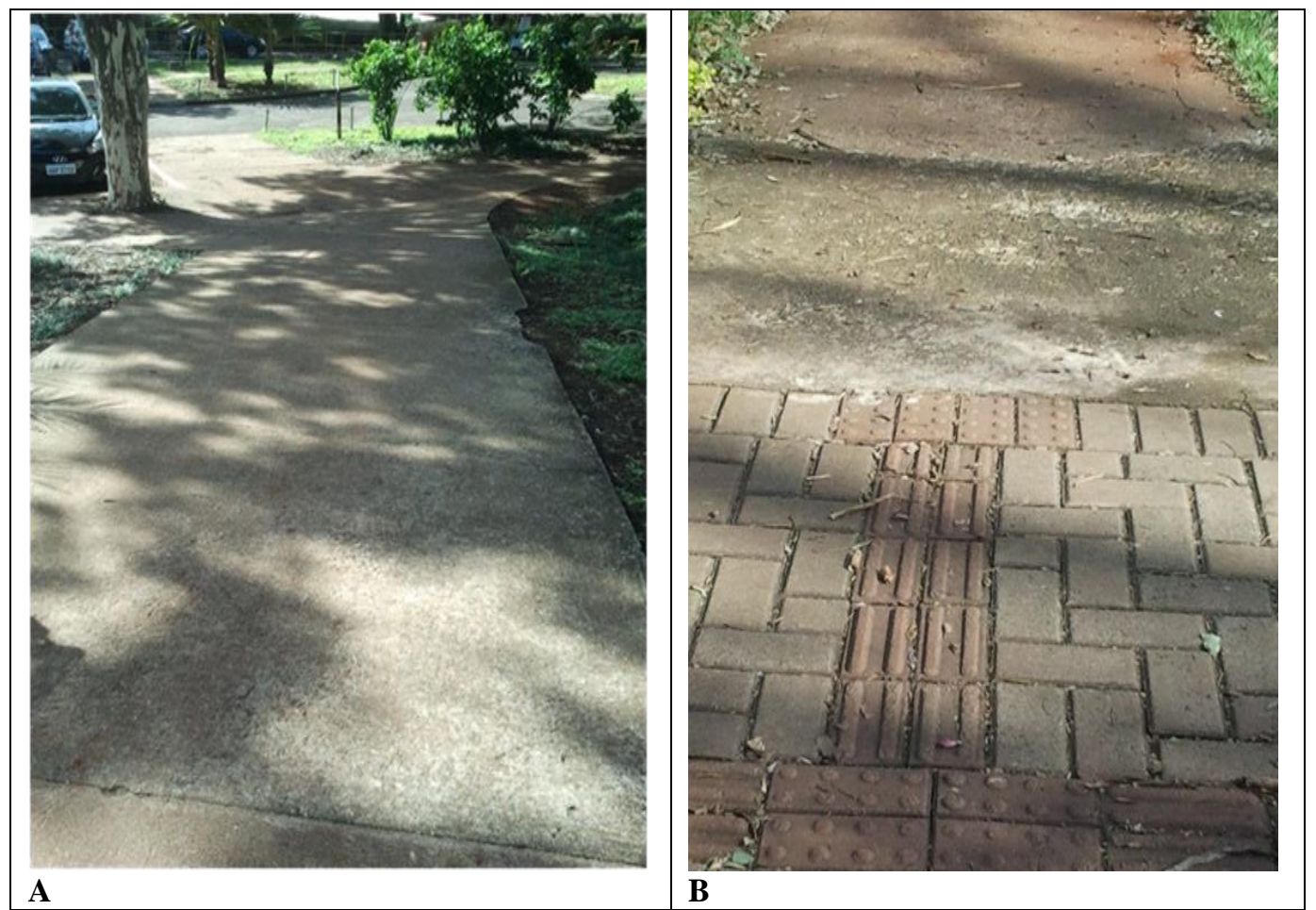

Fonte: Acervo pessoal, 2014.

Com base na observação direta da realidade em relação à acessibilidade na Universidade Estadual de Maringá-UEM, percebe-se a inexistência de símbolo internacional de acessibilidade nos estacionamentos, edificações ou indicando a existência de equipamentos acessíveis em determinados locais. Tais símbolos internacionais de acessibilidade devem ser em pictograma branco sob fundo azul ou opcionalmente em branco e preto, afixados em locais visíveis ao público, principalmente em locais que indicam entrada e saída (ABNT, NBR 9050, 2004).

Os acessos a entradas e saídas devem prever: superfícies regulares, continua, estável e antiderrapante; percurso livre de obstáculos; escadas, rampas ou equipamentos eletrônicos para vencer desníveis; piso tátil de alerta e direcional e; símbolo internacional de acesso para indicar, localizar e direcional adequadamente as pessoas com mobilidade reduzida.

A sinalização tátil deve ser instalada de acordo com o sentido de deslocamento do fluxo de pessoas, apresentar diferenciação de textura em relação ao piso adjacente, sendo necessário quando da ausência ou descontinuidade de guia de balizamento, com largura entre $20 \mathrm{~cm}$ a $60 \mathrm{~cm}$, 


\section{Periádica Eletrânica

podendo exceder em casos de obstáculos suspensos. O dimensionamento dos mesmos deve estar de acordo com a norma ABNT, NBR 9050, com altura dos relevos entre $3 \mathrm{~mm}$ e $5 \mathrm{~mm}$

O piso tátil de alerta, tem a função de indicar as opções de direção a um indivíduo com ausência ou baixa visão, sinalizar a existência de obstáculos durante o percurso, evitando acidentes. Entretanto, o percurso não pode ser obstruído e nem haver interrupção, sem indicação de opções de deslocamento.

Durante o levantamento de dados a campo foi identificado à existência de obstáculos suspensos, tais como placas, orelhões e árvores no percurso de pedestres, sem piso tátil de alerta e direcional para indicar novas alternativas de deslocamento. Outro fator a ser mencionado são os pisos em desníveis, degradados e sem sinalização para indicar a acessibilidade, as edificações e equipamento presentes nas imediações.

\section{CONCLUSÃO}

A instituição de ensino encontrar-se inserida em uma área consolidada da cidade constitui-se em um espaço de passagem e permanência, não só da população universitária, mas também da comunidade externa, que frequenta o local tanto como estrutura viária quanto para acessar serviços locais. Todavia, a mesma apresenta calçadas irregulares, que podem contribuir para a queda e rampas fora dos padrões estabelecidos, sem guia tátil ou corrimão em ambas as extremidades, dificultando a locomoção de pessoas com mobilidade reduzida.

Estudos como este, alertam e fomentam discussões sobre a problemática das barreiras arquitetônicas no perímetro urbano, em especifico os espaços públicos das instituições de ensino. Frequentadores que apresentam algum tipo de limitação à locomoção poderiam ter suas vidas facilitadas se houvesse uma maior preocupação com os equipamentos disponibilizados, através de uma adequada acessibilidade.

\section{REFERÊNCIAS}


AGUIAR, F. O. Acessibilidade Relativa dos Espaços Urbanos para Pedestres com Restrições de Mobilidade. Tese (Doutorado - Programa de Pós-Graduação em Engenharia de Transportes e Área de Concentração em Planejamento e Operação de transportes) Escola de Engenharia de São Carlos da Universidade de São Paulo: São Carlos, 2010. Disponível em: www.teses.usp.br/teses/disponiveis/18/.../tde-21042010-193924/?\&lang. Acesso em: 22 de Julho de 2014.

ASSOCIAÇÃO BRASILEIRA DE NORMAS TÉCNICAS. ABNT NBR 9.050: Acessibilidade de Pessoas Portadoras de Deficiência a Edificações, Espaços, Mobiliário e Equipamentos Urbanos. Rio de Janeiro, 2004. Disponível em: www.centroruibianchi.sp.gov.br/usr/.../ABNTNBR9050_2004. Acesso em: 30 de julho de 2014.

COSTA,A. D.; MEIRA,F.A.;A IMPORTÂNCIA DE FORMAR PROFISSIONAIS COMPROMETIDOS COM A ACESSIBILIDADE E A INCLUSÃO SOCIAL, 2008. Disponível em: periodicos.ufpb.br/ojs/index.php/extensaocidada/article/.../3906/7944. Acesso em 28 de jul de 2014.

DUARTE,C.R.; COHEN, R. . Acessibilidade aos Espaços do Ensino e Pesquisa: Desenho Universal na UFRJ - Possível ou Utópico? In: NUTAU 2004: Demandas Sociais, Inovações Tecnológicas e a Cidade, 2004, São Paulo. Anais NUTAU 2004. Disponível em: http://www.proacesso.fau.ufrj.br/artigos/Acessibilidade_aos_Espacos_de_Ensino_Publico__NUTAU_2.pdf. Acesso em: 28 de Jul de 2014..

MARTINS, N. D.; AUGUSTO, B. Q. T. ACESSIBILIDADE NO MEIO URBANO: UM ESTUDO DE CASO NO JARDIM UNIVERSITÁRIO EM MARINGÁ-PR. III Simpósio de Pós Graduação em Engenharia Urbana. SIMPGEU, 2012. Disponível em: http://www.eventos.uem.br/index.php/simpgeu/simpgeu/paper/view/914/555. Acesso em: 22 de julho de 2014.

SEPED- Mobilidade Acessível na Cidade de São Paulo. Publicação da Comissão Permanente de Acessibilidade (CPA) da Secretaria Especial da Pessoa com Deficiência e Mobilidade Reduzida (SEPED). Disponível em: www.mobilize.org.br/.../mobilidade-acessivelna-cidade-de-sao-paulo.pd. Acesso em: 30 de Julho de 2014.

NUNES, A. L. et al. Acessibilidade e inclusão social no campus da universidade estadual de Maringá/PR. In: XXXV Congresso Brasileiro de Educação em Engenharia - COBENGE,2007. Disponível em: www.abenge.org.br/.../384-Diana\%20Carla\%20Rodrigues\%20Lima.pdf. Acesso em: 30 de julho de 2014.

TRAVASSOS C., CASTRO M, S, M. Determinantes e desigualdades sociais no acesso e na utilização dos serviços de saúde. In: Políticas e sistema de saúde no Brasil. Rio de Janeiro: Fiocruz, Cebes; 2008. p. 215-243.

UNIVERSIDADE ESTADUAL DE MARINGÁ.CPA - Comissão Própria de Avaliação Portaria №. 1.193/2005-GRE . Disponível em:

http://www.cpa.uem.br/Download/1\%20\%20RELATORIO.pdf. Acesso em: 28 de julho de 2014. 